\title{
Bautizar, nombrar, legitimar, apadrinar. El bautizo cristiano en poblaciones indígenas. Altos de Arica, 1763-1833
}

\section{Baptise, name, legitimise, be a godparent. The Christian baptism in indigenous populations. Altos de Arica, 1763-1833}

Xochitl Inostroza Ponce ${ }^{1}$ https://orcid.org/0000-0002-8704-2080

${ }^{1}$ Centro de Estudios Culturales Latinoamericanos, Universidad de Chile. Ignacio Carrera Pinto 1025, Macul, Santiago, CHILE. Email: xochitl@uchile.cl

\begin{abstract}
Resumen
El ritual del bautizo fue uno de los primeros aspectos que las poblaciones indígenas adoptaron del cristianismo, sin embargo, ha sido difícil medir el grado de incorporación del rito cristiano a las prácticas indígenas. Expondré las razones que me llevan a proponer que el bautizo había sido adoptado como parte de la ritualidad cotidiana de los pueblos andinos de los Altos de Arica a fines del período colonial, relacionado con diversas dimensiones simbólicas, tales como el acto de nombrar y apadrinar, así como el registro de la legitimidad que garantizaba ciertos derechos hereditarios. El análisis se ha realizado a partir de las informaciones contenidas en los libros de la parroquia de Belén, que comprende los registros de todos los pueblos indígenas que componían la doctrina.
\end{abstract}

Palabras claves: doctrinas, evangelización, vida cotidiana.

\begin{abstract}
The ritual of baptism was one of the first aspects that indigenous peoples adopted from Christianity, however, it has been difficult to measure the level of incorporation of this sacrament [aspect of Christian rituality] into the indigenous practices. I will explain the reasons that lead me to propose that baptism had been adopted as a common ritual in the Andean towns of the Altos de Arica during the late colonial period, which was related to various symbolic actions, such as giving a persons name, pointing a godparent but also with the registration of legitimacy that guaranteed certain hereditary rights. The analysis is based on the information contained in the books of the parish of Belén, which includes the records of all the indigenous peoples who composed the doctrine
\end{abstract}

Keywords: doctrine, evangelization, daily life.

Recibido: 4 julio 2016. Aceptado: 2 marzo 2017 


\section{Introducción}

Según Bernard y Gruzinski, el padrinazgo cristiano fue aceptado tempranamente en América debido a ligeras similitudes entre este rito y costumbres prehispánicas, relacionadas con el ciclo vital. Los autores comentan que las informaciones de diversos cronistas muestran bastantes semejanzas con ritos realizados para dar la bienvenida a la nueva vida. Sahagún, por ejemplo, utilizó el término "bautizo" "para describir la práctica de la imposición de un nombre al recién nacido, ejecutado por la partera que saludaba la llegada del niño con agua a fin de "purificar". En otros casos, el bautizo cristiano fue asociado al rito de corte de pelo "que confería al infante un status y una identidad" (1986, p. 195). Así, diversos escritos coloniales abordan temáticas relacionadas con el bautizo y su incorporación en las poblaciones indígenas (Poma de Ayala, 2008 [1615]; Álvarez, 1998 [1588], entre muchos otros). La mayoría de estos textos se enfocan en los intentos tempranos del cristianismo de imponer el rito. El presente artículo se centra más bien en el resultado de ese proceso.

Ya pasados varios siglos de evangelización (Marzal, 1983; Estenssoro, 2003; entre muchos otros), hay evidencias que muestran que el bautizo cristiano había sido adoptado por las poblaciones indígenas. En el Itinerario para párrocos de indios, por ejemplo, el obispo de Quito Alonso de la Peńa Montenegro indica que el bautismo era para los indios "causa de respeto y reverencia", pese a que le inquietaba la manera que tenían de celebrarlo: "[...] los Indios las mas vezes mienten, y quieren con pretexto de que están enfermos los niños, bautizarlos luego para disponer despacio sus fiestas para quando les ponen Oleo, y Crisma, que ya todas sus alegrías las manifiestan con borracheras" (1754, p. 352). En este punto se debe destacar que en las crónicas de los primeros tiempos de la conquista, las borracheras estaban asociadas a contextos rituales (Molina, 2007 [1575]; González, 2002).

En la actualidad, se han registrado en la provincia de Arica estos dos tipos de bautizos. En primer lugar, el doméstico, previo al rito cristiano:
[...] una ceremonia familiar que se realiza a los pocos días de vida del bebé y consiste en rezos y aplicación de agua con sal, con el objeto de recibir y proteger al infante de posibles 'males' que pueden afectarle en ese período. La realiza una pareja (familiar o no) elegida por los padres, quienes asumen la calidad de 'padrinos de agua'. La segunda, el bautizo, es el tradicional rito cristiano [...] (Carrasco, 2003, pp. 93-94).

En otros escenarios también se ha reflexionado tanto sobre el significado e imaginario asociado al bautizo en el cristianismo temprano (Jensen, 2012) como de la participación indígena en el proceso evangelizador (Hass, 2014).

En el valle de Azapa se ha documentado además el rito del corte de pelo, que sigue al bautizo propiamente, pero que también cumple una función en la conformación de la identidad social del bautizado: “[...]se realiza más o menos entre los 3 y 5 años; como parte de la preparación del rito hay que elegir padrino, que es quien tiene el privilegio de cortar el primer mechón” (Ríos, 1988, p. 69; Carrasco, 2003).

En el presente artículo no voy a detenerme en las múltiples dimensiones que podría implicar el agua del bautizo (Ossio, 1978) y sus posibles asociaciones con el acto mismo de parir, pues esos aspectos escapan de los registros parroquiales. Por lo tanto, me limitaré a fundamentar las razones que me llevan a proponer que el bautizo cristiano gozaba de un espacio fundamental en la vida ritual de los pueblos andinos de los Altos de Arica a fines del período colonial y las implicancias que este acto conllevaba, relacionadas con diversas dimensiones simbólicas, tales como el acto de nombrar y apadrinar, así como con el registro de la legitimidad que garantizaba los derechos inherentes a la descendencia. La mayor parte de esta evidencia se ha extraído del análisis de los libros de la parroquia de Belén, que comprende los registros de los 10 asentamientos que componían la doctrina de Belén en las postrimerías del de la colonial (Figura 1), correspondientes a 4844 registros. En este sentido, hago referencia a las normativas coloniales que regulaba los sacramentos cristianos que fueron mencionados en la documentación de la parroquia (todas 


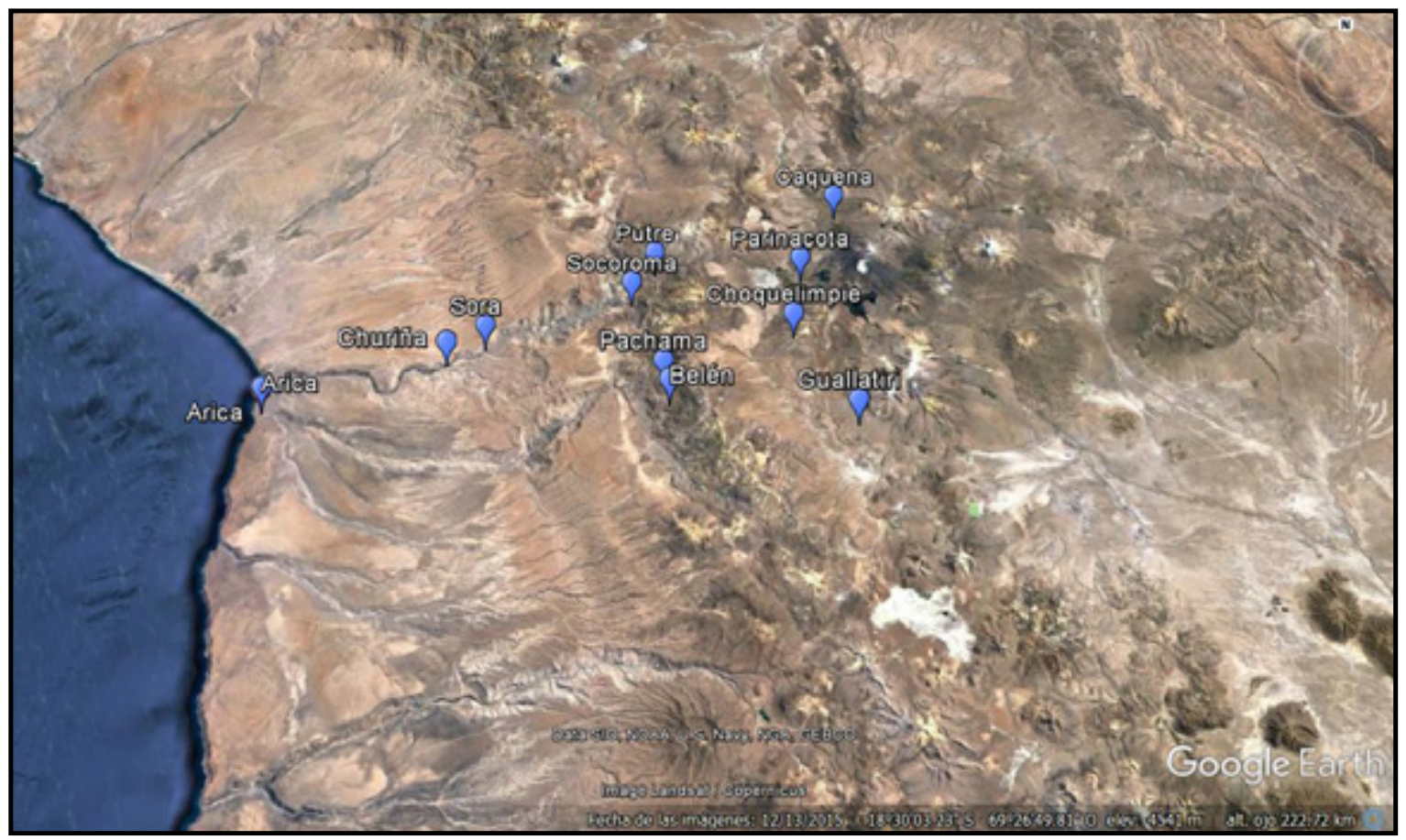

Figura 1. Asentamientos indígenas en el actual territorio de Chile que componían la doctrina de Belén.

ellas anteriores en cuanto a la temporalidad de los registros que contienen los libros de Belén), por lo que no incluyo otros referentes del catolicismo americano. El análisis se plantea desde un punto de vista etnohistórico, cuyo fundamento central se encuentra en documentación histórica de origen eclesiástico, pero recurriendo a información etnográfica que da cuenta de situaciones similares que nos muestran posibles significados y simbolismos en las prácticas indígenas con respecto al ritual cristiano.

Varios aspectos de la historia de los pueblos indígenas de la doctrina de Belén durante la época colonial han sido abordados anteriormente por otros autores (Hidalgo, 1978, 2004a, 2004b; Hidalgo y Durston, 1998; Durston e Hidalgo, 1999; Hidalgo y Castro, 2004; Choque, 2009; Choque y Muñoz, 2016; entre otros). También se han desarrollado diversos aspectos del proceso de evangelización en el área norte de Chile (Van Kessel, 1989, 1996; Castro et al., 2009, Chacama, 2009; Hidalgo, 2011; Pereira, 2013; Guzmán, 2013; Díaz et al., 2014). De los aspectos que nos interesan ahora, podemos resumir que la doctrina de Belén fue creada en 1777, escindiéndose de la doctrina de Codpa debido a las grandes distancias que separaban a los diecisiete pueblos que la componían, que hacían difícil la labor del único párroco que asistía a todos los pueblos del Cacicazgo. Cuando asumió, en 1778, el cura vicario Mariano Pacheco de Peñalosa, comentaba las precarias condiciones en que había encontrado la doctrina:

[...] tan desamparada que mal podría nombrarse tal sino como una mera reducción de indios, pues (como a U.S. Iltma. informaron los indios) nunca ni en alguno de los pueblos de la jurisdicción, se sabía lo que era enseñar la Doctrina y mucho menos se oía su necesaria explicación, careciendo los feligreses de la Divina palabra y de los Santos Sacramentos, pues los Ayudantes del Cura antes de su división, sólo se aparecían en ciertos tiempos a fiestas y recoger las obenciones (Barriga, 1948, p. 279).

En un trabajo anterior, hemos observado otros aspectos de la religiosidad cristiana indígena en la doctrina de Belén (Inostroza, 2013b). 


\section{El rito del bautizo}

Los sacramentos cristianos fueron registrados en el mundo europeo en el cuerpo jurídico conocido como Siete Partidas del sabio rey Don Alfonso (1256-1265). Su vigencia es tal en el continente americano, que se las encuentra mencionadas en los libros de la parroquia de Belén, cuyos registros se extienden desde 1763 a 1833 (AN PB). Según este cuerpo normativo, el bautismo "[e]s el sacramento que limpia el cuerpo y purifica el alma, á virtud de las santas palabras y agua que se usan" (Alfonso X, 1843-1844, p. 14). De la misma forma en los Andes el agua era símbolo de depuración y salud, que prevenía contra la enfermedad (Molina 2007 [1575], p. 48, 133). Pero en América, además, el bautismo se asoció con la conversión de la población autóctona al cristianismo, y sus efectos se sienten aún en la actualidad. Por ejemplo, Harris observó entre los laymi de Bolivia que a los bebés prebautismales se les llama moros, "una clara referencia a su condición de preconversos" (en Platt, 2002, p. 144; Millones 2007). Lo mismo registró Platt en la sociedad macha:

\section{[...] el nacimiento del individuo se relaciona} con un cataclismo mito-histórico que habría estado en los orígenes de la misma sociedad. Las almas ancestrales precristianas son pensadas como pequeños diablos gentiles, que moran dentro de la tierra (ukhu pacha) y deben entrar en los vientres de las mujeres para dar vida y energía a los embriones humanos en gestación. De tal modo, los antepasados paganos se reencarnan como bebés cristianos, proceso que se percibe como análogo a la conversión religiosa de la sociedad andina en el siglo XVI (Platt, 2002, p. 128).

En la zona de Arica, se han informado situaciones similares:

Después del nacimiento, a los nińos se les tiene que bautizar en el más corto tiempo, tampoco los huérfanos y abandonados se quedan sin recibirlo, cuando no se realiza el bautizo la familia y la comunidad sufrirán muchas desgracias. Si un niño muere sin que sus padres hayan tenido la posibilidad de bautizarlo, es considerado 'moro' e irá al limbo y la comunidad será objeto de desgracias naturales (Ríos, 1988, p. 166).

Algunas propuestas sugieren que los rituales corresponden a un soporte de memoria, una archiescritura (Derrida, 1998) que en este caso tendría como función perpetuar una memoria familiar y comunal. Tristan Platt, por ejemplo, muestra la clara funcionalidad que tendría el bautizo para las poblaciones originarias; la de convertirlos en cristianos, lo que a su vez implicaba mantener un derecho fundamental:

Para los indígenas, la conversión de un estado anterior de gentilidad fue un requisito para mantener sus derechos a la tierra bajo el gobierno espańol. Por lo tanto, el problema para los nativos andinos fue cómo compatibilizar la autoctonía, que necesariamente implicaba la descendencia sustantiva desde los paganos, con su renacimiento como conversos andinocristianos. Parte de la solución parece haber consistido en repetir el proceso de conversión con cada nuevo nacimiento (El destacado es mío) (Platt, 2002, p. 129).

En este sentido, el bautizo no solo convertía a los indios en cristianos sino que, además, los incluía en el pacto colonial, que les garantizaba la mantención de sus derechos sobre las tierras ocupadas.

Para que el bautizo fuera válido, debía estar acompañado de una frase inmutable: "Yo te bautizo en el nombre del Padre, del Hijo, y del Espíritu Santo, amén”. Pero en caso de duda, se debía comenzar diciendo: "Yo te bautizo (si no lo estás)..." (Alfonso X, 1843-1844, p. 14). Y las dudas ocurrían frecuentemente, pues el bautizo podía ser realizado por cualquier persona en caso de necesidad. En la doctrina de Belén el $57 \%$ de los registros indica que el bautizo se realizó "subconditione", lo que no responde necesariamente a un "elemento estereotipado de alguna tradición discursiva” (Humanchumo de la Cuba, 2010, p. 181), ya que probablemente se había realizado un primer bautizo doméstico. De hecho, 
en las primeras inscripciones de 1763, el cura Diego de Zaconeta Ramírez y el teniente Pedro Celestino Carrasco utilizaron la frase "rebauticé sub conditione y puse óleo y crisma". ${ }^{1}$ Posteriormente, otros tenientes y curas siguieron indicando el "rebautizo" de los registrados y a partir de 1798 se diferencia entre los bautizos "absolute y solemnemente" de los realizados "subconditione". ${ }^{2}$ En algunos casos incluso se advierte: "constando estar bien bautizada puse óleo y chrisma"; "3 "cerciorado estar bien bautisado", "jurado que estaba bien bautisada una criatura. ${ }^{5}$ En otra frase se hace referencia a dos momentos diferenciados: "asistio al agua y al bautismo". ${ }^{6}$

El Segundo Concilio Limense (1567-1568) había estipulado que el bautizo debía realizarse dentro de los ocho días y el mes de nacidos (Arretx et al., 1983). En la doctrina de Belén, el $45 \%$ de los niños fue bautizado durante el primer mes de vida y el $59 \%$ antes de cumplir los dos meses. Sin embargo, generalmente los sacerdotes no estaban presentes de manera permanente en los distintos pueblos para cumplir esta norma. Un documento de mediados del siglo XVII menciona que estos visitaban los distintos asentamientos de la doctrina de Codpa dos o tres veces al año. ${ }^{7}$ Los libros parroquiales muestran que la situación no había cambiado demasiado para fines del siglo XVIII. Al seguir el recorrido de los bautizos en uno de los años con mayor número de registros en los libros parroquiales, queda clara la rutina seguida por el cura y sus tenientes. En 1778 la ruta del sacerdote Mariano Pacheco de Peñalosa y de fray Fernando de Tapia y Cáceres se iniciaba en el mes de abril bautizando a niños de los pueblos de Putre y Socoroma. Hacia mediados del mes se encontraban en Belén, donde permanecieron todo el mes de mayo. A finales de junio asistieron a las parcialidades de Caquena y al pueblo de Parinacota. En junio volvieron a Socoroma y luego a fines de julio se encontraban nuevamente en Belén, para volver a Socoroma a principios de agosto y estar en

1 Vol. I, f. 1v, 1763. AN PB.

2 Vol. VI, f. 32v, 1798. AN PB.

3 Vol. VI, f. 69v, 1801. AN PB.

4 Vol. VI, f. 70, 1801. AN PB.

5 Vol. VI, f. 81v, 1802. AN PB.

6 Vol. VI, f. 122v, 1806. AN PB.

7 Visita de la doctrina de Codpa y Azapa, y sus anejos. Arica-Codpa, 1650-1891. AAA.
Putre a fines del mes. En septiembre, nuevamente bautizaron en Parinacota y Caquena. A mediados de octubre pasaron por Socoroma, camino al valle bajo, para dirigirse hacia Churiña donde estuvieron a fines del mes. Subieron nuevamente a Socoroma en noviembre, para luego pasar por Pachama a fines de noviembre y terminar el año en Belén.

Los registros de bautizo muestran que el cura y sus asistentes bautizaban en los poblados donde se encontraban y evidencian que durante su ausencia esa función era cumplida por alguien más. Ahora bien, la participación de distintos agentes en el bautizo estuvo estipulada desde las Siete Partidas: "Pueden [bautizar] los sacerdotes; los ordenados de evangelio y epístola en caso de urgencia, y últimamente cualesquiera que tenga uso de razón, y aun el padre, sin que por esto resulte nuevo parentesco" (Alfonso X, 1843-1844, p. 15). En América, la ausencia de sacerdotes propició el hecho que el bautizo fuera realizado por otros agentes cercanos a la comunidad. El obispo Alonso de la Peña Montenegro indica que el cura estaba "obligado en conciencia a enseñar la forma y modo de bautizar a alguno de su beneficio", entre quienes debía incluir a las parteras, pues "son las que mas de ordinario se ven en extremas necesidades" (1754, p. 355). Debió ser generalizado el bautizo por estas mujeres, ya que el Sexto Concilio (1772) solicitó a los visitadores eclesiásticos que examinaran si "las obtetrices o parteras están instruidas en la materia y forma del Baptismo e intención que deben tener para administrarlo en caso de necesidad" (Vargas Ugarte, 1952, p. 56). En la actualidad, en la zona aymara del norte de Chile, las parteras "son mujeres mayores reconocidas en la comunidad y generalmente madres o suegras" (Carrasco, 1998, p. 91).

Esta permisividad hace muy posible que el bautizo además fuera realizado por algún familiar, por alguien cercano a la comunidad o por alguien instruido en el ritual. Hasta hace algunos años la costumbre continuaba en el valle de Azapa: "Si no hay sacerdote, la ceremonia puede ser realizada por cualquier persona de la familia, éste echará el agua y dará un nombre a la criatura" (Ríos, 1988, p. 67).

El Sexto Concilio había estipulado además que en todos los pueblos y anexos se nombrasen fiscales que ayudaran a los curas en el ejercicio de la enseñanza 
de la doctrina (Vargas Ugarte, 1952), aunque estos ayudantes fueron nombrados desde los primeros tiempos de la Conquista (Álvarez, 1998 [1588]). En el período de este estudio, en los Altos de Arica fueron designados en este cargo al menos cuatro personas: Pascual Condori, de Putre (1790), ${ }^{8}$ Francisco Flores (1791), ${ }^{9}$ Bernardo Vásquez (1793) ${ }^{10}$ y Miguel Mollo, los tres últimos en Socoroma (1801). ${ }^{11}$ En este sentido la mayor permanencia en el tiempo del cura doctrinero en el pueblo de Belén (cabecera de la doctrina) explicaría la necesidad de nombrar fiscales en los otros dos pueblos con mayor densidad demográfica: Socoroma y Putre (Hidalgo, 1978; Hidalgo et al., 2004). Además, en los registros parroquiales se reconoce a distintos sujetos bautizando. Entre los indígenas se menciona a Eugenio Guanca, quien sería alcalde mayor de Belén en 1806, Petrona Mollo de Parinacota ${ }^{12}$ y Basilio Quebaillo de Putre. ${ }^{13}$ En algunos casos, el registro indica los detalles: "a quien habia bautisado en caso de necesidad el sacristan de la Iglesia de Putre nombrado Ildifonso Gutierres a quien examine y halle que havia administrado bien el dicho bautismo, y por eso supli las seremonias que faltaban"; ${ }^{14}$ "a quien extra fortem avia bautisado Ambrocio Martínes Maestro Cantor de este anexo de Putre". ${ }^{15}$ También hay registros de sujetos extraños a la comunidad que habían realizado el sacramento, varios de ellos, españoles: "a quien en caso de necesidad bautiso Don Diego Portillo vesino de la Villa de Oruro y residente en el pueblo de Guallatiri"; ${ }^{16}$ "a quien bautiso extra fortem en caso de necesidad Agustín Laredo, español residente en el pueblo de Choquelimpe, de quien Don Mariano Herrera ygualmente residente en aquel pueblo me ynformo lo hiso en su presencia sin faltar en cosa alguna necesaria a la devida administracion del sacramento"; ${ }^{17}$ "a quien bautiso D. Antonio Auñon". ${ }^{18}$ Incluso en algunas situaciones, la identidad del que había bau-

8 Pliegos matrimoniales Arica-Belén. 1694-1856. AAA.

9 Pliegos matrimoniales Arica-Belén. 1694-1856. AAA.

10 Vol. III, f. 196v, 1793. AN PB.

11 Vol. VII. f. 38, 1801. AN PB.

12 Vol. VI, f. 68v, 1801. AN PB.

13 Vol. VI, f. 59, 1801. AN PB.

14 Vol. VI, f. 59, 1801. AN PB.

15 Vol. VI, f. 89v, 1803. AN PB.

16 Vol. VI, f. 116v, 1806. AN PB.

17 Vol. VI, f. 117, 1806. AN PB.

18 Vol. VI, fs. 130-130v, 1807. AN PB. tizado era desconocida: "a quien bautiso en caso de necesidad una persona española que supo hacerlo". ${ }^{19}$ Estos ejemplos muestran de qué modo el rito del bautizo estaba en gran medida en manos de los feligreses, siendo muy probable que el bautizo de agua fuera realizado mayormente por alguien de la familia o la comunidad, o por algún cristiano que había auxiliado a la mujer en el momento del parto, pues el bautizo de agua debió realizarse de forma casi inmediata al nacimiento. En cambio, el rol del cura doctrinero y de sus tenientes quedaría restringido a la confirmación del bautizo con óleo y crisma. Ahora bien, esta situación es coherente con lo que ha expresado Van Kessel en cuanto a que durante el siglo XVIII en Tarapacá el buen funcionamiento del aparato litúrgico-parroquial se estableció bajo "la asistencia de cantores, fabriqueros y demás funcionarios laicos de menor rango [10]" (Van Kessel, 1989). Esta interpretación coincide con las de Pereira (2013) y Díaz et al. (2014).

\section{Nombres y apellidos}

Otro aspecto visible en los registros de bautizos es el acto de nombrar que acompañaba al bautizo: "jurado de que esta bien bautisada una criatura puse oleo y chrisma a la que se le havia puesto por nombre Ildefonso"; ${ }^{20}$ "a la que se le havia puesto el nombre de Ignacia”. ${ }^{21}$ En una inscripción incluso se diferencia al sujeto que "puso" nombre del que ofició como padrino, en este caso, dos sujetos de prestigio en Belén: Clemente Vega y Francisco Ocharan.

"Año del Señor de mil setesientos ochenta y
sinco en veinte días del mes de enero. Yo el
Lizenciado Don Clemente Rodrigues the-
niente de cura en el Pueblo de Belen bapti-
se sub condisione puse oleo y chrisma a una
criatura de edad de dos meses aquien puso
por nombre Clemente Vega de Gregorio hijo
Legitimo de Sebastian Chamvi y de Isabel
Mamani originarios del aneso de Guallatiri
fue su Padrino francisco hucharani a quien le
adberti la obligación y parentesco espiritual.

19 Vol. VI, f. 99, 1803. AN PB.

20 Vol. VI, f. 81v, 1802. AN PB.

21 Vol. VI, f. 85v, 1802. AN PB. 
Y para que conste lo firme. Clemente Rodrigues". Nótese el nombre del padrino, Francisco Ocharan, quien posteriormente ocupó los cargos de alcalde mayor y secretario en el cabildo indígena (Inostroza, 2013a).

Como mencioné anteriormente, este acto se realizaba al momento de "echar el agua", por lo que sin duda era un rito de gran significación. Por otra parte, al nombrar, se pretendía concretar la conversión a la nueva fe, por lo que desde los primeros tiempos de la conquista se había prohibido utilizar nombres de "gentiles", lo que sumaría a la violencia intrínseca del acto de nombrar (Derrida, 1998) una violencia explícita colonialista, como la relatada por José de Arriaga en 1621:

De aquí en adelante ningún indio, ni india se llamará con nombre de las Huacas, ni del rayo, y así, no se podrá llamar Curi, Manco, Micsa, Chacpa, ni Líbiac [...] y al que a su hijo pusiese alguno de estos nombres, le serán dados cien azotes por las calles, y el cura o vicario de esta doctrina procederá contra el, como contra relapso en idolatría. Y los que hasta aquí se han llamado con algunos de los dichos nombres mando se les quiten, $y$ se acomoden a llamarse con otros sobrenombres, de los Espańoles o de los Santos [...] (citado por Alaperrine-Bouyer, 2007, p. 34).

Por eso llevar un nombre cristiano era símbolo de haber sido bautizado y, por lo tanto, convertido a la nueva fe: "Hay otros infieles cristianos, disimulados engańadores que, no siendo bautizados, se han puesto nombres de cristianos" (Álvarez, 1998 [1588], p. 159).

De alguna manera se llegó a un consenso, pues el Tercer Concilio Limense estipuló que los indios debían llevar nombres cristianos, pero podían mantener sus apellidos; los hombres, el de sus padres y las mujeres, el de sus madres.

Para que eviten los yerros que en reiterar baptismo y matrimonio indios no conocidos suelen acaecer; totalmente se les quite a los indios el usar de los nombres de su gentilidad e ydolatría y a todos se les ponga nombres en el baptismo cuales se acostumbran entre christianos, y de estos mismos los compelan a usar entre sí. Más los sobrenombres para que se diferencien, procúrese que los varones procuren los de sus padres, y las mujeres los de sus madres (Vargas Ugarte, 1951, p. 327).

Los sujetos indígenas de varias doctrinas adoptaron apellidos indígenas mientras eran bautizados con nombres españoles, situación que se repite en localidades andinas; en Atacama por ejemplo se mantuvieron apelativos indígenas (Martínez, 1998). Durante la época colonial muchos indígenas fueron bautizados con apellidos espańoles, pero en algunos casos es probable que el apelativo se debiese a la castellanización de uno de origen aymara (Inostroza, 2013a). Mendinacelli realiza un recuento de varias investigaciones centradas en nombres de indígenas, la mayoría centradas en períodos más tempranos y de los cuales destacan características que no se observan en este caso, tales como la transmisión paralela de los apellidos, la referencia a cargos en vez de apellidos, entre otros (2003; Tandeter y Acosta 2002). En la doctrina de Belén se observan tanto apellidos indígenas - de origen quechua y aymaracomo españoles, que eran transmitidos de manera patrilineal, con excepción de los hijos de madres solteras, que recibían el apellido de su madre -ya fueran hombres o mujeres- por lo que no se observan diferencias etarias o de género en la transmisión de los patronímicos como las identificadas en los primeros registros de la población andina (Robinson, 2003, pp. xxvi-xxviii).

Volviendo a la acción de nombrar, las frases identificadas más arriba insinúan que el nombre era impuesto por quien bautizaba en primera instancia, con agua. La imposición de nombres cristianos asociados al santo del día, al patrono o patrona del pueblo o a algún otro de la devoción del bautizador o de la familia del bautizado establecía así una alianza, un pacto de conversión y fidelidad de los preceptos morales del cristianismo. Aunque esta alianza -siguiendo a Menard (quien analiza el efecto del registro del nombre en las inscripciones civiles para el caso mapuche)- no implica necesariamente un sometimiento, 
[...] no busca disolver la diferencia de los enemigos en la homogeneidad de una amistad definitiva, sino que, por el contrario, la alianza marca esta diferencia como un acto de amistad heterogéneo sobre un fondo de enemistad potencial y permanente. En esta potencia de devenir el otro mediante el pacto y la alianza reencontramos la figura del mana como doblez y suplemento [...] (Menard, 2010, p. 70).

Salomon y Grosboll, por su parte, observaron esta especie de pacto con seres divinos en la transición desde el mundo prehispánico al mundo colonial: "Con el paso de los años, los nombres prehispánicos de alto rango se concedieron prioritariamente a los hijos varones, mientras que la jerarquía onomástica se erosionó en el lado femenino. Se nota un contrasentido interesante; muchas mujeres indígenas de la época colonial llevaban el nombre de la madre de las deidades principales, participante y originadora de un mundo primordial (Salomon et al., 2009, p. 18).

En la parroquia de Belén, el 13\% de las niñas bautizadas recibió el nombre de María, cifra que asciende a $20 \%$ si se considera a quienes recibieron un nombre compuesto iniciado con él, tales como María del Carmen, María de la Concepción, María de la Encarnación, María del Rosario, entre otras. Dicha proporción es muy alta, pues los demás apelativos no superan el $6 \%$ en el caso de los hombres y el $5 \%$ en las mujeres. Otros nombres femeninos usuales fueron: Juana (5\%), Manuela, Petrona, Francisca (4\%), Josefa, Gregoria, Paula, Tomasa, Juliana (2\%). En los hombres, el más utilizado fue Mariano (6\%), nombre que probablemente provenga del cura Mariano Pacheco, quien fue cura vicario durante gran parte del período de este registro. Le siguen Juan y Manuel (5\%), Pedro y Francisco (4\%), José (3\%), Gregorio, Tomás, Andrés, Antonio, Felipe (2\%). Solo en algunos casos los nińos fueron nombrados a partir de los santos del día de su bautizo o nacimiento; en otros casos, adquirían el de algún familiar, ya sea un abuelo, tío o hermano. Este último caso sobre todo cuando un hermano mayor había fallecido. En el caso de gemelos, muchas veces estos eran nombrados de la misma manera, aunque en ocasiones a uno de ellos se le diferenciaba con un segundo nombre. Sobre este aspecto, varias crónicas y textos de los primeros tiempos de la evangelización registraron las connotaciones que se atribuían a mellizos o gemelos. En los ritos y tradiciones de Huarochirí se indica que se les llamaba Curi o Kuri, por atribuirlos al rayo (Taylor, 1987), "quedando este nombre por apellido de sobrenombre en la succesion de los tales [...]" (Duviols, 1974-76, en Taylor, 1987, p. 489). En la sociedad macha, de manera similar, los gemelos se consideran un par perfecto "porque están relacionados el uno al otro como el lado derecho del cuerpo lo está con el izquierdo". Aún más, una mujer que daba a luz gemelos se consideraba capaz de maldecir a otras (Platt, 1976). El significado que representan los hijos nacidos al mismo tiempo de un mismo vientre en la zona de Arica en la actualidad es descrita por Waldo Ríos: "Los mellizos siguen aún siendo vistos con bastante cuidado y respeto, porque están influenciados por los espíritus, se les considera como hijos queridos de los espíritus y con doble bendición" (Ríos, 1988, p. 64), en una situación similar a la descrita por Platt (1980).

A diferencia de otras localidades, donde era frecuente el cambio de nombres y apellidos a lo largo de la vida de las personas (Zonabend, 1981), en la doctrina de Belén se encuentran pocos casos de cambios de nombres y/o apellidos, pero uno de ellos es bastante singular. Vicente Larva en su tercer matrimonio (con Melchora Peres) se registró como Santiago Larva. ${ }^{22}$ Anteriormente, en el Padrón de 1813, casado con Manuela Mamani, ya había sido inscrito como Santiago Larva, bajo el título de don, debido a su cargo de regidor (Hidalgo et al., 1988, p. 45). La pareja fue apuntada además con una hija pequeña de tan solo cinco ańos, llamada María del Carmen. En algún momento la patrona del pueblo de Belén fue la Virgen del Carmen.

Es sintomático que en este posible cambio de nombre se haya transmutado al santo patrono del pueblo: Santiago. Probablemente el cambio de nombre se deba entonces a motivos religiosos, siguiendo una costumbre de otras latitudes. ${ }^{23}$ De esta manera, el

22 Vol. VII, f. 139, 1819. AN PB.

23 Desde el siglo XVIII, el cacique de Sabaya adoptó el nombre del santo patrono del pueblo. Com. pers. Gilles Rivière en un seminario organizado por José Luis Martínez en la Universidad de Chile. 10 de diciembre 2015. 
nombre cristiano establecía un estrecho vínculo con el santo al que aludía, que podía incluso mantenerse hasta en la muerte. Francisco Ocharan, por ejemplo, en su testamento pidió que al morir su cuerpo fuera "mortajado con el abito de mi Padre Señor San Francisco". ${ }^{24}$ Por otra parte, la inscripción del apellido indígena según los patrones occidentales representa -esta vez siguiendo a Platt- "la base sustancial de la identificación política y jurídica del indio originario con la tierra" (2002, p. 150). En otras palabras, el bautizo establecía una alianza y una filiación (Menard, 2010) cuyo registro perpetuaba el pacto colonial: asegurar la conversión que daba derecho y acceso a tierras de reparto. Esto explica por qué a algunas mujeres, y también a unos cuantos hombres, sobre todo forasteros, no se les registraran apellidos. Seguramente no les eran necesarios.

Para poder observar la frecuencia de apellidos en la doctrina, analicé el registro de los distintos pueblos de la revisita de 1773 (Hidalgo et al. 2004), ya que por una parte coincide con las inscripciones parroquiales y, por otra, permite observar la distribución de los apelativos en un momento determinado. De esta manera, los apellidos más frecuentes fueron: Mamani (4\%), Choque (3\%), Guanca (3\%), Condori $(2 \%)$, Larba (2\%), Yucra (2\%), Cutipa (2\%), Vásquez (2\%).

El apellido Mamani, halcón (Bertonio 1956 [1612], p. 213), estaba presente masivamente en los pueblos de Socoroma, Belén y Guallatiri, y en menor medida en Putre, Pachama, Sora y Caquena. El apellido Choque, oro (Bertonio 1956 [1612], p. 59), estaba presente prácticamente en todos los pueblos, con mayor frecuencia en Belén, Putre y Socoroma, pero también en Guallatiri, Pachama, Sora, Caquena, Choquelimpe y Parinacota. El apellido Huanca o Guanca estaba en Belén y Putre mayoritariamente, pero también en Socoroma, Parinacota, Pachama, Guallatiri, Caquena y Sora. El apellido Condori, cóndor (Bertonio 1956 [1612], p. 52), era más común en Putre y Socoroma, pero también en los otros pueblos. El apellido Larva ${ }^{25}$ era

24 Testamento de Francisco Ocharan, 1794. Legajo 50. AN NA. Ver Inostroza 2013ª.

25 Larva: Las palabras más similares que encontramos en aymara son Lari (parientes de la madre [101]) Laurahua (Plumas del pájaro Caque [198]) (Bertonio 1956 casi exclusivo de Belén, aunque en 1773 hay algunos casos en Pachama y uno en Socoroma. Los de apellido Yucra o Yugra, camarones (González Holguín, 1952 [1608], p. 373), se encontraban principalmente en Putre, luego en Socoroma y Caquena, pero también había algunos en Sora y uno en Belén. Los de apellido Vásquez, principalmente en Belén, pero también en Socoroma y Caquena, y uno en Putre y Sora. Otros apellidos frecuentes en la doctrina eran Alanoca, Apaz/Apaza, Calle/Calli, Choqueguanca, Cusi, Humiri o Humire, Marca, pueblo (Bertonio 1956 [1612], p. 217), Mita, tiempo (Bertonio 1956 [1612], p. 223), Mollo, Nina, la llama del fuego o lumbre encendida propiamente (Bertonio 1956 [1612], p. 233), Quispe, Sisa, Tarque, Flores, Ramos, Cruz, Carbajal, Inquiltupa, López, Cáceres, Gutiérrez, Medina, Blanco, Luque, Bara o Vara, todos ellos con un $1 \%$ en 1773.

El método de reconstitución de familias (Fleury y Henry, 1956) ha permitido identificar algunos cambios de nombres y unos pocos cambios de apellidos. Aunque no son generalizados en la población, es interesante notar estas permutas, aunque en varios casos pueden deberse también a errores de quienes escribían los registros. Algunos nombres se registraron de forma diversa, por ejemplo, Feliciano o Phelipe: Phelipe Larva, en su registro de matrimonio con Victoria Nina, ${ }^{26}$ fue registrado como Feliciano Larva en la lista de tributarios que pagan diezmos. ${ }^{27}$ Luego en 1813 se le registró nuevamente como Feliciano, con su misma esposa (Hidalgo et. al., 1988, p. 50). Ocurrió lo mismo en el caso de María Carmen Condori, de Belén, quien fue registrada como María, ${ }^{28}$ María Carmen ${ }^{29}$ y Carmina. ${ }^{30}$

Algunas situaciones, más que errores, parecen cambios voluntarios. Por ejemplo, cuando Hilario Larva se casó con María Santos Larva en 1775. Los padres de Hilario eran Francisco Larva y María Mamani, los padres de ella fueron registrados como Francisco

[1612]).

26 Vol. III, f. 122v, 1780. AN PB.

27 Demarcación y lista de contribuyentes de la Doctrina de Belén. Arica-Belén. 1694-1856. AAA.

28 Vol. IV, f. 8, 1778. AN PB.

29 Vol. I, f. 107, 1776 y vol. IV, f. 39v, 1782. AN PB.

30 Vol. IV, f. 61, 1784. AN PB. 
Barrio y María Mamani. ${ }^{31}$ En el registro de bautizo de su hijo Nicolás a ella se le registró como María Santos Larva. ${ }^{32}$ Luego en el registro de defunción de su hijo ${ }^{33}$ y en su propio registro de defunción se le inscribió con el apellido Larva. ${ }^{34}$ No la encontramos en la revisita de 1773 , por lo que es probable que fuera forastera. Lo que hace aún más extraño el caso es que los padres de ambos tuvieran los mismos nombres: Francisco Larva y María Mamani. ¿Se deberá esto a un error del que registró o se estará escondiendo un parentesco muy cercano? De momento no tengo respuesta, pero la inclusión de los apellidos Barrio y Santos en uno de los registros me lleva a pensar que fue una acción intencional de quien realizó en registro, buscando establecer diferencias en el patronímico de ambos cónyuges. En otro caso, Remigio Marca, de origen aparentemente forastero, se casó en 1781 con Petrona Guanca. ${ }^{35}$ Años más tarde cambió su nombre, por el de su padre, Juan. ${ }^{36}$ Se descubren además pocos casos de cambios de apellidos. Uno de los más notorios es el de Paula Rojas. Se le inscribe con este nombre en el registro de su matrimonio con Santos Mamani. ${ }^{37}$ Luego, en los registros de bautizo de sus hijos, se menciona su nombre como Paula Inti. ${ }^{38}$ En otra ocasión su apellido como Intimarka ${ }^{39}$ y en otro como Maita [marka?]. ${ }^{40}$

Finalmente, se observan algunas evoluciones de apellidos, por ejemplo, el apellido Coria, que con el tiempo fue transformado en Correa. Por ejemplo: Santiago Coria, de Pachama, se casa en 1810 con Margarita Larva de Belén. ${ }^{41}$ En el Padrón de 1813, se inscribe a Santiago Correa casado con Margarita Larva en Pachama (Hidalgo et al., 1988, p. 54). Por otra parte, tengo la impresión de que los apellidos Cruz y Santos, fueron impuestos intentando reemplazar otros, como en un caso que he mencionado, frente a coincidencia de apellidos.

31 Vol. III, f. 102, 1775. AN PB.

32 Vol. IV, f. 2, 1778. AN PB.

33 Vol. II, f. 58, 1780. AN PB.

34 Vol. II, f. 67v, 1781. AN PB.

35 Vol. III, f. 126, 1781. AN PB.

36 Vol. IV, f. 59v, 1784; f. 166v, 1794. AN PB.

37 Vol. III, f. 118v, 1779. AN PB.

38 Vol. IV, f. 35v, 1781; f. 60v, 1784; f. 131v, 1791. AN PB.

39 Vol. IV, f. 2v, 1778. AN PB.

40 Vol. I, f. 77, 1772. AN PB.

41 Vol. VII, f. 91, 1810. AN PB.

\section{Padrinos y madrinas}

Según la documentación colonial, los doctrineros debían señalar a los padrinos (De la Peña Montenegro, 1754). Lo expresaron las disposiciones del Tercer Concilio Limense: "[...] en cada pueblo o parrochia de indios, se señalase un padrino para los que se baptizan; el señalarle empero a este, será propio del ordinario, el cual podrá también señalar más que uno, como viere convenir al número de gente, con tal de que los assi señalados sean ciertos y tales que se les pueda encomendar la enseñanza de los hijos espirituales" (Vargas Ugarte, 1951, p. 326).

Anteriormente, el Primer Concilio había dispuesto la necesidad de nombrar solo un padrino, para evitar la cognación espiritual (Vargas Ugarte, 1951). Sin embargo, en las inscripciones de la doctrina de Belén en varios casos se mencionan dos o tres padrinos e incluso en algunas ocasiones se diferencia al padrino o madrina de agua y al padrino de óleo y crisma. Las características de ambos tipos de padrinos en la parroquia de Belén indican que la designación de un padrino por parte del cura podría haberse realizado para el bautizo de óleo y crisma, mientras que la elección o designación del padrino/madrina de agua, respondería a circunstancias más familiares o domésticas. Esta situación se observa claramente en un caso en particular. En 1785 Florentino Alanoca y Ana Lopes, tributarios de Parinacota, bautizaron a su hijo Mariano, "asistió al bautismo un indio cuyo nombre se ignora”, y al óleo Doña María Gonsales. ${ }^{42}$ Debido al título de doña, es probable que esta madrina fuera una mujer española. En varios casos se indica que el primer bautizo fue realizado por personas externas a la comunidad: por ejemplo, en el bautizo de Teodora Churata, de Putre, al cual "asistió al bautismo una mujer forastera cuio nombre se ignora". ${ }^{43}$ En Socoroma, asistió un bautismo un forastero llamado Andrés "cuyo apelativo se ignora". ${ }^{44}$

Otras situaciones demuestran los dos padrinazgos que acompañan a las dos instancias del rito. En 1806, en Parinacota, Victoria Humiri asistió al bautismo de Pablo Humiri, mientras que Josef Choque,

42 Vol. IV, f. 63, 1785. AN PB.

43 Vol. VI, f. 23, 1797. AN PB.

44 Vol. IV, f. 171, 1794. AN PB. 
vecino de Socoroma, asistió al óleo. ${ }^{45}$ Otros casos distinguen un bautizo privado de otro solemne: en el bautizo de Rosa, hija legítima de Francisco Luque y Anselma Pérez de Sora, asistió al bautismo privado Meleano Queguaillo, de Sora, y al solemne Theresa Urdanivia de Lluta. ${ }^{46}$ En varias otras ocasiones se mencionan por separado a los padrinos. En 1778 se registró en Belén el bautizo de Manuel, hijo legítimo de Juan Contreras y Estefanía Marca. Asistió al bautizo Juan Marca, quien debió ser familiar de la madre del niño; y al óleo, don Diego Phelipe Cañipa, ${ }^{47}$ cosa excepcional pues muy raras veces el cacique de Codpa participó como padrino en esta doctrina.

Al revisar el registro completo se pueden observar frecuencias de ciertas prácticas recurrentes en un período. Desde 1790 comienzan a registrarse casos en que dos cónyuges cumplían los dos roles de padrino, uno asistiendo al bautizo y el otro al óleo y crisma. Desde 1802 incluso se empieza a mencionar a tres padrinos, el primero asistiendo al bautizo, luego una pareja -generalmente cónyuges- que asisten al óleo y crisma. La distinción entre el padrino del bautizo y el del óleo y crisma se presenta hasta 1808. En algunos casos, el que "echó el agua" tuvo que asumir el padrinazgo. Esta situación se observa en los siguientes casos. En 1801 el cura Antonio Ponce y Andrade indica que Petrona Mollo "suplió las ceremonias" en el bautizo de Jacinto, hijo legítimo de José Calisaya y Sebastiana Mamani, naturales de Parinacota, por lo que le "advirtió la obligación que tenía". ${ }^{48}$ Una última costumbre que se evidencia en los registros es que la asistencia al ritual podía ser realizada por un representante. Sería el caso del bautizo de Mariano Guanca, de Socoroma, asistiendo a él don Martín Serrano, y al óleo Miguel Guanca a nombre de don Martín. ${ }^{49}$ En 1791 se bautizó en Belén a Camilo, hijo legítimo de Tomás Larva y Antonia Cruz; asistió al bautizo Manuela Cutipa a nombre de José Larva. ${ }^{50}$ En Socoroma, asistió al bautizo Petronila Mamani, del mismo pueblo, a nombre de Dionicia

45 Vol. VI, f. 121v, 1806. AN PB.

46 Vol. VI, f. 54v, 1800. AN PB.

47 Vol. IV, f. 2, 1778. AN PB.

48 Vol. VI, f. 68v, 1801. AN PB.

49 Vol. IV, f. 134v, 1791. AN PB.

50 Vol. IV, f. 138v, 1791. AN PB.
Cusimamani. ${ }^{51}$ Pese a la existencia de estos casos, una mirada a los registros en su conjunto no permite sacar conclusiones respecto a un protocolo estandarizado en la elección de los padrinos, sino que estos más bien parecen responder a prácticas que varían en el tiempo y que no siguen una norma uniforme.

Por otra parte, tanto hombres como mujeres participaron de igual manera en los padrinazgos: $52 \%$ las mujeres y $48 \%$ los hombres (de un total de 5980 padrinos). Además, la observación detallada de quienes cumplieron el rol de padrino y madrina con mayor frecuencia demuestra que en muchos casos corresponden a sujetos de prestigio, entre ellos, españoles, mestizos, forasteros y autoridades étnicas. Entre ellos se menciona a: dońa Cecilia de Tapia, española proveniente de La Paz, vecina de Belén; ${ }^{52}$ Josefa Loredo, española de la ciudad de Oruro, residente en Choquelimpe; ${ }^{53}$ Isidro Quiroga, español residente en Churińa y vecino de Belén; doña Tadea Almonte Vélez de Guevara, natural de la ciudad de Arequipa ${ }^{54}$ dońa Manuela Liendro, vecina de Tacna ${ }^{55}$ Magdalena Emagaray, quien fue esclava del cura Mariano Pacheco y Peñalosa, posteriormente residente en Socoroma; ${ }^{56}$ don Gregorio Urbano Almonte, presbítero natural de Arequipa, ${ }^{57}$ entre otros. La participación constante en el padrinazgo de sujetos foráneos a la comunidad puede ser interpretada desde la perspectiva del "otro" (Ossio, 1992; Barth, 1976), es decir, sujetos ajenos a ella -pero a la vez con lazos que los conectan- que posibilitan la autoidentificación. Por otra parte, bien pudo instituir -o quizás reafirmar- redes parentales con otras localidades, extendiendo así las "fronteras rituales" de la comunidad (Adrián, 2012; Ramos, 2015). Ahora bien, tanto los forasteros como las autoridades indígenas tienen un aspecto en común: el prestigio. En cuanto a esto, se han observado diversos tipos de padrinazgos (de bautizo, matrimonio, confirmación, verticales y horizontales) que dan cuenta de la función de mediador en el reconocimiento de un grupo familiar en formación como ente autónomo

51 Vol. VI, f. 56v, 1800. AN PB.

52 Vol. VI, f111v, 1805; f. 136, 1807. AN PB.

53 Vol. VI, f. 117, 1806.AN PB.

54 Vol. VI, f. 229v, 1809. AN PB.

55 Vol. VI, f. 39v, 1799. AN PB.

56 Vol. VI, f. 28v, 1798; f. 92, 1803. AN PB.

57 Vol. VI, f. 232, 1820; f. 242v, 1822. AN PB. 
al interior de la comunidad (Albó y Mamani, 1980, p. 287; Isbell, 1974; Malegreau, 1980; Spedding, 1998; Ferreiro y Fernández, 2013; Fernández, 2018). En este sentido, a partir del prestigio del padrino o la madrina en la doctrina de Belén, queda en evidencia su rol en el buen posicionamiento de la familia y el individuo al interior del grupo.

\section{Bautizo y legitimidad en espacios indígenas}

En los registros parroquiales, así como en las informaciones matrimoniales correspondientes a la parroquia, se indica la condición legítima o natural de los hijos, estos últimos, hijos de "padres no conocidos" (frase utilizada incluso cuando se conoce el nombre de la madre). No se utiliza el término "ilegítimo" para referirse a los hijos nacidos fuera del matrimonio. Según Margadant, había una diversidad de situaciones que implicaban la ilegitimidad de los hijos: naturales, adulterinos, bastardos, nefarios, incestuosos, sacrílegos, manceres (Margadant, 1991). Ninguna de estas categorías fue utilizada en las partidas de nacimiento de la doctrina de Belén, solo hijos naturales, lo que implica simplemente que nacieron fuera del matrimonio.

De un total de 4844 nińos bautizados en la doctrina de Belén entre 1763 y 1833, el 13,5\% correspondía a hijos naturales, lo que contrasta con una amplia mayoría de hijos legítimos (86\%).

En alguna oportunidad, destaqué que este índice de hijos ilegítimos "se considera bajo en comparación a estudios realizados en asentamientos de carácter urbano, mientras que parece confirmar lo observado en otros espacios rurales" (Inostroza, 2014, p. 72). En aquella oportunidad presenté la siguiente tabla (Tabla 1), que me interesa reproducir aquí para poner en evidencia la distinta condición de los espacios étnicos en contraposición a los asentamientos pluriétnicos. Así, la Tabla 1 expone las localidades en orden creciente respecto del porcentaje de ilegitimidad.

Este cuadro se publicó en un artículo de carácter demográfico sobre el matrimonio en Belén (Inostroza, 2014). El valor de San Luis de la Paz es el único que presenta una disminución en el porcentaje de legitimidad con el transcurso de los ańos (Gil Montero, 2000; Tandeter, 2000; Gil Montero, 2004; Klein, 1986; Rabell, 1992; Carbajal, 2009; Mellafe y Salinas, 1998; Muñoz, 1990; McCaa, 1983; Avendaño, 2005; Ponce, 1978; O’Phelan, 2006; Rodríguez, 2006). En mi análisis del cuadro propuse que "la ilegitimidad en sociedades indígenas no se explica según si un espacio corresponde a una zona rural o urbana, sino más bien, al grado de 'cohesión social' que presentan las comunidades" (Inostroza, 2014, p. 76), lo que es observado más fácilmente en espacios indígenas rurales. Esta cohesión, siguiendo a Robichaux, "se basa en la participación en un sistema ritual, efectivo y prácticamente obligatorio" (Robichaud, 2001, p. 119), que en los Altos de Arica del período Tardocolonial incluía ritos católicos como el matrimonio (Inostroza, 2014; Inostroza, 2013b) y el bautizo.

Y es que las dos etapas del bautizo (el de agua y el de óleo y crisma) en los Altos de Arica se realizaba tempranamente. Como mencioné, 59\% de ellos fueron realizados antes de cumplir un mes de vida la criatura. Esta urgencia pudo tener dos causas: en primer lugar, el ritual cristiano, que solicitaba el bautizo dentro de los primeros días de vida. Por otra parte, la evidencia demográfica propone que se intentó bautizar a los nińos antes que la muerte acechara, lo que ocurría entre los tres meses y los dos años de vida (Inostroza, 2014).

$\mathrm{Al}$ analizar anteriormente el rito del bautizo se establecieron dos fundamentos: su papel como garante en la conversión y, como consecuencia, la inclusión de los sujetos en el pacto colonial. Se puede agregar que el bautizo establecía la legitimidad de los hijos, aspecto fundamental para instituir la herencia (Ferreiro, 2012). Al respecto Morin señala: "Estas finalidades se entrelazan con el contexto jurídico de una sociedad donde el testimonio escrito tiene más valor que el oral y donde la legitimidad -y la posibilidad de probarla- rige la herencia, la sucesión y el ascenso social" (Morin, 1972, p. 392).

El acceso a derechos inherentes a la descendencia requería de un soporte garante. Un ejemplo situado en un contexto cercano permite comprender esta dimensión. En 1832, Pedro Ara presentó en Tacna 
Tabla 1. Porcentajes de ilegitimidad. Comparación localidades. 1692-1849.

\begin{tabular}{|c|c|c|c|c|}
\hline Localidad & Período & Escenario & Clas. étnica & $\begin{array}{c}\% \\
\text { ilegitimidad }\end{array}$ \\
\hline $\begin{array}{l}\text { Santa Catalina } \\
\text { (Jujuy) }\end{array}$ & 1790-1799 & rural & indígena & 0,18 \\
\hline Potosí & $1692-1811 ?$ & minero & indígena & 1 \\
\hline Potosí & $1692-1811 ?$ & minero & indígenas criollos & 4 a 28 \\
\hline Chayanta (Bol) & $1692-1811$ & rural & indígena & 5 a 10 \\
\hline Rinconada (Jujuy) & $1780-1831$ & rural & indígena & 7,0 a 19,1 \\
\hline Amatenango (Mx) & $1785-1816$ & rural & indígena & 7,6 \\
\hline $\begin{array}{l}\text { Santa Catalina } \\
\text { (Jujuy) }\end{array}$ & $1752-1759$ & rural & indígena & 8,4 \\
\hline $\begin{array}{l}\text { Santa Catalina } \\
\text { (Jujuy) }\end{array}$ & $1780-1829$ & rural & indígena & 10,2 a 22,5 \\
\hline Cochinoca (Jujuy) & $1780-1830$ & rural & indígena & 11,2 a 19,7 \\
\hline S. Luis de la Paz (Mx) & $1715-1810$ & rural & pluriétnica & 12,6 a 5,7 \\
\hline Doctr. Belén (Arica) & $1763-1833$ & rural & indígena & 13,5 \\
\hline Bolaños (Mx) & $1740-1822$ & minero & pluriétnica & 21 \\
\hline La Ligua (Ch) & $1700-1849$ & rural & pluriétnica & 21,5 \\
\hline Casablanca & $1740-1800$ & rural & pluriétnica & 23 \\
\hline Puchuncaví & $1700-1799$ & rural & pluriétnica & 26 \\
\hline Melipilla & s.XVIII & rural & pluriétnica & 28 \\
\hline Quillota & s.XVIII & rural & pluriétnica & 28 \\
\hline Malloa & $1744-1810$ & rural & pluriétnica & 29 \\
\hline Petorca & $1840-1864$ & rural & pluriétnica & 29,1 \\
\hline Tunja (Colombia) & $1750-1819$ & urbano & pluriétnica & 32,3 \\
\hline San Felipe & $1740-1800$ & rural & pluriétnica & 33 \\
\hline Petorca & $1740-1790$ & rural & pluriétnica & 34 \\
\hline Valparaíso & $1727-1830$ & urbano & pluriétnica & 34 \\
\hline Santa Marta (Areq) & $1800-1809$ & urbano & pluriétnica & 34,2 \\
\hline La Paz & $1775-1777$ & urbano & pluriétnica & 40 \\
\hline Colombia & s.XVIII & urbano & pluriétnica & 45 a 60 \\
\hline Guadalajara & s.XVIII & urbano & pluriétnica & 50 \\
\hline
\end{tabular}


una denuncia contra Pedro Estaca por pretender tener derecho de principal:

Y porque en cuanto a la pretensión del Principalato es falso lo que alega, porque es hijo el dicho Pedro Estaca de Pablo el Cantor (a quien no menciona en su escrito) el que nunca fue Principal, ni pretendió serlo porque conocía no tener derecho a ello; de parte materna tampoco puede fundar su pretensión; pues fue India particular, todo lo que se puede probar si fuera necesario con bastante amplitud..$^{58}$

En pueblos (como los de la doctrina de Belén) que seguían generalmente un patrón patrilineal, el descender de sujetos originarios permitía el acceso -probablemente en forma hereditaria- a las tierras de reparto (Inostroza, 2016); por eso era importante legitimar a los descendientes e, incluso más, registrar ese derecho a través de un rito y un escrito: el bautizo. Esto podría explicar la mayor tendencia a la legitimidad que se observa en distintas zonas indígenas de la América colonial.

\section{Comentarios finales}

Comencé este artículo haciendo mención a los textos que dan cuenta de la incorporación temprana del bautizo en las poblaciones indígenas, asociado a prácticas previas al cristianismo. En él di cuenta además de las variadas informaciones etnográficas que han registrado situaciones similares a las reveladas en este estudio. ¿Son estas manifestaciones evidencias de continuismo cultural? Como menciona Burke, se debe tener en cuenta que los simbolismos cambian con el transcurso del tiempo (Dresden, 1975, en Burke, 2000, p. 246). Los materiales históricos a partir de los cuales se construyó este análisis no dan cuenta de los contenidos y las significaciones, solo de las prácticas. En este escenario no puedo más que reconocer los aspectos que manifiestan los registros de bautizo de la parroquia de Belén y hacer referencia a las situaciones que otras investigaciones han abordado respecto de las mismas temáticas, especialmente las etnográficas, que

58 Ara Pedro con Estaca Pedro por Derecho de principal, 1832. Legajo 3, Pieza 18. AN JA. Referencia en Hidalgo, 2004. tienen el valor de acercarse más a las profundidades de los actos.

En los Altos de Arica de la segunda mitad del siglo XVIII, el bautizo cristiano fue acogido en dos dimensiones. En primer lugar, asociado a la práctica de "echar el agua", que era realizada por alguna persona que estuviera presente en el nacimiento o primeros días de vida del recién nacido, y que en algunos casos incluso era efectuada por transeúntes y sujetos externos a la comunidad. Esta etapa del rito se ha observado en épocas actuales, tanto en la provincia de Arica y Parinacota como en localidades cercanas de Chile y Bolivia, que entregan pistas sobre su significación y contenido. Algunas de las prácticas registradas etnográficamente en la actualidad en los pueblos de la zona están presentes en las costumbres que se observan desde el siglo XVIII, tales como la función de las parteras en el bautizo de agua, la distinción de dos tipos de bautizo, la dimensión más familiar del bautizo de agua, entre otras. En segundo lugar, el rito cristiano propiamente, realizado por el cura, que consistía en confirmar el bautizo con óleo y crisma. Es así como algunas de las prácticas relacionadas con el bautizo parecen tener su origen en la organización del culto cristiano en la etapa colonial: el primer bautizo de agua, realizado por laicos suplió la ausencia del cura doctrinero en localidades lejanas del centro religioso, falencia que se mantuvo constante en el tiempo y que explica en gran medida la supervivencia de tradiciones culturales que había propiciado el proceso evangelizador en los Andes, relacionadas con el culto cristiano.

Es muy probable que el bautizo cristiano haya sido adoptado por las poblaciones indígenas en los Altos de Arica en períodos anteriores a los de este estudio, y que se haya asociado a tradiciones preliminares, al menos de las que emergieron de las recomendaciones iniciales de los primeros concilios limenses. Sin embargo, los libros de la parroquia de Belén permiten comprobar que al finalizar el período colonial el rito del bautizo no solo se había cristalizado como parte del mundo simbólico y se había constituido en un componente fundamental del sistema ritual de la comunidad, sino también de la ritualidad cotidiana, lo que demuestra que la comunidad participaba activamente de él, a partir principalmente del bautizo de agua, que a su vez establecía el padrinazgo. Es por 
ello que con este sacramento emergen generalmente dos tipos de padrinos que asisten a cada una de las ceremonias, que en algunos casos corresponde a la misma persona o a una pareja de casados. Una mirada al período completo me permite sostener que no hubo un patrón único en la elección de los padrinos a lo largo del tiempo. Queda pendiente analizar en profundidad las relaciones de compadrazgo que se conforman a partir del bautizo, así como indagar sobre las causas que otorgaron un rol trascendente al establecimiento de redes de parentesco ritual. En coherencia con el proceso de evangelización, se puede afirmar que el rito del bautismo gozó de gran significación en las poblaciones indígenas que habitaban los Altos de Arica al finalizar el período colonial. Ahora bien, dicha significación tiene dimensiones simbólicas de diversa índole, tanto a partir de "echar el agua” y otorgar el nombre como al establecer un parentesco ritual con algún otro miembro de la familia o de la comunidad. En este último aspecto, la participación de sujetos foráneos (residentes o no en la misma doctrina) instituía o reafirmaba redes parentales con otras localidades, extendiendo así las "fronteras rituales". Es probable la existencia de un aspecto de naturaleza jurídica del bautizo, relacionado con el hecho mismo del registro, que permitía instituir la legitimidad de los hijos, constituyéndose en una garantía que resguardaba derechos a los que se accedía a partir de la descendencia.

El bautizo de agua daba pie a la elección del nombre, asunto en que intervenían diversos motivos culturales: el nacimiento de gemelos, la muerte anterior de un hermano, en algunos casos el santo patrono del día del bautizo, entre otros. Los apellidos, por otra parte, eran transmitidos generalmente de manera patrilineal, salvo en el caso de hijos de mujeres solteras, quienes recibían el apellido de la madre, en muchos casos, apelativo del abuelo materno. Los apellidos más comunes se encuentran en gran parte de los pueblos, aunque hubo casos de apellidos provenientes de localidades exclusivas, es decir, de un pueblo o dos. Se detectaron algunos casos aislados de cambios de nombres o apellidos, respondiendo a situaciones particulares. El registro del bautizo, la inscripción del nombre y el apellido debieron contener un halo de sacralidad, pues representa la materialización de un rito que además de los significados trascendentes del mismo, reconocía una legitimidad que otorgaba derechos comunales. Vuelvo a resaltar los altos índices de este aspecto que se han observado en poblaciones indígenas de la América colonial y que bien pueden responder a esta causa. Estos, así como la frecuente recurrencia al bautizo y al matrimonio, nos hablan de sociedades en las que los principales ritos del cristianismo no solo habían sido incorporados, sino que las comunidades participaban activamente de ellos, incluso bautizando, lo que demuestra que se habían apropiado de ciertas funciones religiosas, que reflejan la manera en que el culto cristiano había pasado a formar parte de la religiosidad local. Su importancia fue tal, que la etnografía ha registrado situaciones que convergen, al menos en forma, con las efectuadas a fines del período colonial en los Altos de Arica.

Esta incorporación a las prácticas cotidianas del acto del bautizo refleja además otra situación. Mencioné que a su llegada el nuevo vicario denunciaba la falta de doctrina cristiana que había encontrado en sus feligreses. Pues bien, es muy probable que al menos esta dimensión del culto cristiano ya se hubiese cristalizado como conocimiento y ejercicio en el quehacer cotidiano de las poblaciones indígenas en los Altos de Arica. Como indiqué, desde los primeros registros se da cuenta del "rebautizo", lo que nos habla de una práctica ya conocida y extendida del bautizo de agua. Por otra parte, el problema de los nombres también se puede tomar como argumento, pues desde los primeros registros parroquiales, correspondientes a 1763, no hay ni una sola mención a las dificultades que pudo generar la imposición de un nombre cristiano y, por el contrario, la transmisión del apellido por vía paterna ya parece haber estado institucionalizada desde mucho antes. La incorporación del acto del bautizo de agua en el mundo cotidiano de los pueblos indígenas de la Parroquia de Belén refleja, además, que ese primer nombre, cristiano, era impuesto por quien bautizaba, probablemente algún miembro de la familia o cercano. Reflejo, esto también, no solo de la adopción de los rituales que se asociaban con el culto católico, sino que con sus preceptos y con las normas jurídicas que este contenía. Es así como la ausencia de conflicto es la mejor evidencia del protagonismo que había alcanzado en la vida cotidiana el bautizar, nombrar, apadrinar y legitimar, dimensiones todas contenidas en un solo acto ritual. 


\section{Agradecimientos}

Agradezco el apoyo prestado por el proyecto FONDECYT Postdoctoral 3180287 titulado "Población, familia y vida cotidiana. Doctrina de Belén y sus fronteras (1750-1820)". También debo gratitud a los profesores Jorge Hidalgo y Herbert Klein por guiar mi investigación doctoral, de la cual este artículo formó parte. A Soledad González por organizar este dossier y a Helena Horta por su trabajo editorial. A los evaluadores anónimos y a Pablo Larach por sus valiosos comentarios.

Este artículo corresponde a un capítulo de la tesis doctoral de la autora, que ha sido revisado y modificado en algunos aspectos para esta publicación.

\section{Abreviaturas}

AAA Archivo Arzobispal de Arequipa.

AN Archivo Nacional.

JA Judiciales de Arica.

NA Notarios Arica.

PB Parroquia de Belén.

\section{Referencias citadas}

Adrián, M. (2012). Acerca de las unidades de análisis en el sur andino colonial a partir de un estudio de caso: Chayanta, siglo XVI - siglo XVIII. Surandino Monográfico, 2 (2). Recuperado de http://www.filo.uba.ar/ contenidos/investigacion/institutos/ravignani/prohal/ mono.html

Alaperrine-Bouyer, M. (2007). La educación de las elites indígenas en el Perú colonial. Lima: Instituto Francés de Estudios Andinos - Instituto de Estudios Peruanos Instituto Riva-Agüero.

Albó X. y Mamani, M. (1980). Esposos, suegros y padrinos entre los aymaras. En Mayer, E. y Bolton, R. (Comps.). Parentesco y matrimonio en los Andes (pp. 283-326). Lima: Pontificia Universidad Católica del Perú.

Alfonso X (1843-1844). Las siete partidas del Rey don Alfonso el Sabio. París: Lecointe y Lasserre Editores.
Álvarez, B. (1998 [1588]). De las costumbres y conversión de los indios del Perú. Memorial a Felipe II. Madrid: Ediciones Polifemo.

Arretx, C., Mellafe, R. y Somoza, J. (1983). Demografía histórica en América latina. Fuentes y métodos. San José: CELADE.

Avendaño, R. (2005). Demografía histórica de la ciudad de Tunja a través de los archivos parroquiales. 1750-1819. Tunja: Universidad Pedagógica y Tecnológica de Colombia.

Barriga, V. (1949). Memorias para la Historia de Arequipa. Tomo IV. Arequipa.

Barth F. (Comp.) (1976). Los grupos étnicos y sus fronteras. La organización social de las diferencias culturales. México, D.F: Fondo de Cultura Económica

Bernard, C. y Gruzinski, S. (1986). Les enfants de l'Apocalypse: la famille en Méso-Amérique et dans les Andes. En Burgière, A., Klapisch-Zuber, C., Segalen, M. y Zonabend, F. Histoire de la famille, vol. II (pp. 157209). París: Editorial Armand Colin.

Bertonio, L. (1956 [1612]). Diccionario castellano-aymaral aymara-castellano.

Carbajal, D. (2009). Reflexiones metodológicas sobre el mestizaje en la Nueva Espańa. Una propuesta a partir de las familias del Real de Bolaños, 1740-1822. Letras Históricas, 1, 19.

Carrasco, A. M. (1998). Constitución de género y ciclo vital entre los aymarás contemporáneos del Norte de Chile. Chungara, 30, 87-103.

Carrasco, A. M. (2003). Llegando al Mundo Terrenal: Embarazo y Nacimiento entre los Aymaras del Norte de Chile. En Montecino, S., Castro, R. y De la Parra, M. A. (Eds.). Mujeres: Espejos y Fragmentos (pp. 84-97). Santiago: CIEG.

Castro, N., Chacama, J. y Mir, R. (2009). Excitar y subyugar. Pastoral de la imagen y poblaciones indígenas en Arica Colonial. Diálogo Andino, 34, 25-43.

Chacama, J. (2009). Imágenes y palabras, dos textos para un discurso: La prédica pastoral en los Andes coloniales. Doctrina de Codpa (Altos de Arica), siglo XVIII. Diálogo Andino, 33, 7-27. 
Choque, C. (2009). El Colesuyu meridional: Espacio de articulación económica y cultural hispano-indígena en la segunda mitad del siglo XVI. Allpanchis, 73-74, 241-267.

Choque, C. y Muńoz, I. (2016). El Camino real de la Plata. Circulación de mercancías e interacciones Culturales en los valles y altos de Arica (siglos XVI al XVIII). Historia, 49(1), 57-86.

De la Peña Montenegro, A. (1754). Itinerario para Parrochos de indios, en que se tratan las materias más particulares, tocantes à ellos, para su buena Administración. Amberes.

Derrida, J. (1998). De la gramatología. México: Siglo XXI.

Díaz, A., Martínez, P. y Ponce, C. (2014). Cofradías de Arica y Tarapacá en los siglos XVIII y XIX. Indígenas andinos, sistema de cargos religiosos y festividades. Revista de Indias, 74(260), 101-128.

Durston, A. e Hidalgo, J. (1999 [2004]). La presencia andina en los valles de Arica, siglos XVI-XVIII: Casos de regeneración colonial de estructuras archipielágicas. En Hidalgo, J., Historia Andina en Chile (pp. 479-506). Santiago: Editorial Universitaria.

Duviols, P. (1974-76). Une petite chronique retrouvée: Errores, ritos, supersticiones y ceremonias de los yndios de la prouincia de Chinchaycocha y otras partes del Piru. Tomo LXIII. París: J. S.A.

Estenssoro, J. C. (2003). Del paganismo a la santidad: la incorporación de los indios del Perú al catolicismo, 15321750. Lima: Institut Français d’Études Andines.

Fernández, F. (2018). Redes de capital social familiar en la región oriental de Jujuy (Argentina) durante las tres primeras décadas del siglo XX. Estudios Atacameños. Arqueología y Antropología Surandinas, 58, 29-48.

Ferreiro, J. P. (2012). El compadrazgo como dispositivo de reclutamiento. Análisis estructural y organización social en el Tucumán Colonial. En Paredes, A. (Comp.), Redes Sociales: Análisis e intervención psicosociales (pp. 1-24) Mendoza: Editorial de la Universidad del Aconcagua.

Ferreiro, J. P. y Fernández, F. (2013). Nupcialidad, compadrazgo y endogamia en las Yungas de Jujuy (Noroeste de Argentina) durante la primera mitad del siglo XIX. Caravelle. Cahiers du monde hispanique et luso-brésilien, 101, 21-57.
Fleury, M. y Henry, L. (1956). Des registres paroissiaux à L'Histoire de la population. Manuel de dépouillement et d'exploitation de l'état civil ancien. París: Institut National D'Études Démographiques.

Gil Montero, R. (2000). Entre la ley y la práctica: la familia en la puna de Jujuy, 1770-1870. En Boleda, M. y Mercado, M. C. (Comps.). SEPOSAL Seminario sobre Población y Sociedad en América Latina (pp. 138-139). Salta: Gredes - Universidad Nacional de Salta.

Gil Montero, R. (2004). Caravaneros y transhumantes en los Andes meridionales. Población y familia indigena en la puna de Jujuy, 1770-1870. Lima: IEP.

González, S. (2002). Condena y tolerancia de la embriaguez en Arica, Tarapacá y Atacama en la segunda mitad del siglo XVIII. Tesis para optar al grado de Licenciado en Historia, Licenciado en Educación y Profesor de Enseñanza Media en Historia y Ciencias Sociales. Facultad de Humanidades, Universidad de Valparaíso.

González Holguín, D. (1952 [1608]). Vocabulario de la lengua general de todo el Perú llamada lengua Qquichua o del Inca. Impr. Santa María.

Guzmán, F. (2013). Las pinturas murales en la Doctrina de Belén. Espacio Regional, 1(10), 85-96.

Haas, L. (2014). Saints and Citizens, indigenous histories of colonial missiones and mexican california. Berkeley: University of California Press.

Hidalgo, J. (1978). Revisita a los altos de Arica efectuada por el oficial real don Joaquín de Cárdenas 1750. Iquique: Universidad del Norte.

Hidalgo, J. (2004a) Cacicazgos del sur occidental andino: origen y evolución colonial. En Historia Andina en Chile (pp. 471-477). Santiago: Editorial Universitaria.

Hidalgo, J. (2004b). Rebeliones andinas en Arica, Tarapacá y Atacama, 1770-1781. En Historia Andina en Chile (pp. 247-270). Santiago: Editorial Universitaria.

Hidalgo, J. (2004c). Historia andina en Chile. Santiago: Editorial Universitaria.

Hidalgo, J. (2011). Redes eclesiásticas, procesos de extirpación de idolatrías y cultos andinos coloniales en el corregimiento de Atacama, siglos XVII-XVIII. Estudios 
Atacameños. Arqueología y Antropología Surandinas, 42, 113-152.

Hidalgo, J., Arévalo, P., Marsilli, M. y Santoro, C. (1988). Padrón de la Doctrina de Belén en 1813: un caso de complementariedad tardía. Arica: Universidad de Tarapacá, Facultad de Estudios Andinos. Departamento de Antropología, Geografía e Historia.

Hidalgo, J. y Castro, N. (2004). El liderazgo étnico en Atacama, Altos de Arica, Tacna y Tarata (siglo XVIII). Chungara. Revista de Antropología Chilena. Volumen especial, 799-811.

Hidalgo, J., Castro, N. y González, S. (2004). La Revisita de Codpa (Altos de Arica) de 1772-73 efectuada por el corregidor Demetrio Egan. Chungara. Revista de Antropología Chilena, 36(1), 103-112.

Hidalgo, J. y Durston, A. (1998). Reconstitución étnica colonial en la sierra de Arica: el cacicazgo de Codpa, 1650-1792. En Historia Andina en Chile (pp. 507-534). Santiago: Editorial Universitaria.

Humanchumo de la Cuba, O. (2010). Textos y ritos del Bautismo indiano en documentos notariales del siglo XVI. Revista Andina, 50, 175-197.

Inostroza, X. (2013a). Dimensiones del liderazgo étnico en el pueblo de Belén: Francisco Ocharán, secretario del cabildo indígena. Altos de Arica (1750-1813). Estudios Atacameños. Arqueología y Antropología Surandinas, 46, 109-126.

Inostroza, X. (2013b). Políticas matrimoniales y prácticas indígenas. Doctrina de Belén, Altos de Arica (17631823). Allpanchis, XLIV(81-82), 245-278.

Inostroza, X. (2014). Matrimonio y familia en sociedades andinas: propuestas desde la reconstitución de familias de Santiago de Tacrama o Belén. Virreinato del Perú (1763-1820). Historia, 47(1), 65-90.

Inostroza, X. (2016). Parroquia de Belén: Población, familia y comunidad en una doctrina de indios. Altos de Arica, 1763-1820. (Tesis para optar al grado de Doctora en Historia, mención Etnohistoria) Facultad de Filosofía y Humanidades, Universidad de Chile, Santiago.

Isbell, B. J. (1974). Parentesco andino y reciprocidad, Kuyaq: los que nos aman. En Alberti, G. y Mayer, E. (Eds.).
Reciprocidad e intercambio en los Andes peruanos (pp. 110152). Lima: Instituto de Estudios Peruanos.

Jensen, R. (2012). Baptismal imagery in early christianity ritual, visual and theological dimensions. Michigan: Baker Academic.

Klein, H. (1986). Familia y Fertilidad en Amatenango, Chiapas, 1785-1816. Historia Mexicana, 36(20), 273286.

Malengreau, J. (1987) Territorios andinos, alianzas matrimoniales y circulación de productos en el norte de Chachapoyas. Revista Andina, 5(1), 93- 138.

Margadant, G. (1991). La familia en el derecho novohispano. En Gonzalbo, P. (Comp.). Familias Novohispanas. Siglos XVI al XIX. Seminario de Historia de la Familia (pp. 27-56). México, D.F.: El Colegio de México.

Martínez, J. L. (1998). Pueblos del chañar y el algarrobo. Los atacamas en el siglo XVII. Santiago: DIBAM - Facultad de Filosofía y Humanidades Universidad de Chile - Centro de Investigaciones Barros Arana.

Marzal, M. (1983). La transformación religiosa peruana. Lima: Pontificia Universidad Católica del Perú.

McCaa, R. (1983). Marriage and Fertility in Chile. Demographic Turning Points in the Petroca Valley, 1840-1976. Colorado: Westview Press.

Mellafe, R. y Salinas, R. (1998). Sociedad y población rural en la formación de Chile actual: La Ligua 1700-1850. Santiago: Ediciones de la Universidad de Chile.

Menard, A. (2010). La lección de escritura de E. R. Smith: archivo y representación en la Araucanía del siglo XIX. En García, M. (Ed.). Archivo: prospectos de arte, Santiago: Centro de Documentación de las Artes.

Medinaceli, X. (2003). ¿Nombres o Apellidos? El sistema nominativo aymara. Sakaka, siglo XVII. La Paz: Instituto de Estudios Bolivianos - Instituto Francés de Estudios Andinos.

Millones, L. (2007). Todos los niños se van al cielo. Lima: Pontificia Universidad Católica del Perú - Instituto Riva-Agüero. 
Molina, C. (2007 [1575]). Relación de las fábulas y ritos de los Incas. Calvo, J. y Urbano, H. (Eds.). Lima: Fondo editorial Universidad San Martín de Porres.

Morín, C. (1972). Los libros parroquiales como fuente para la historia demográfica y social novohispana. Historia mexicana, 3, 389-418.

Muñoz, J. G. (1990). Los hijos naturales en la Doctrina de Malloa. En Pinto, S. (Ed.). Familia, matrimonio y mestizaje en Chile colonial. Serie Nuevo Mundo: Cinco siglos $n^{\circ} 4$ (pp. 35-50). Santiago: Departamento de Ciencias Históricas, Facultad de Filosofía y Humanidades, Universidad de Chile.

O'Phelan, S. (2006). Entre el afecto y la mala conciencia. La paternidad responsable en el Perú borbónico. En O’Phelan, S. y Zegarra, M. (Eds.). Mujeres, familia y sociedad en la historia de América Latina, siglos XVIII-XXI (pp. 37-56). Lima: CENDOC-PUCP - Instituto RivaAgüero - IFEA.

Ossio, J. (1978). El simbolismo del agua y la representación del tiempo y el espacio en la fiesta de la acequia de la comunidad de Andamarca. En Actes du XLII Congrès International des Américanistes, 4 (pp. 377-95). París.

Ossio, J. (1992). El otro en la cosmología andina. En Portilla, M. L., Gutiérrez, M., Gossen, G. y J. Klor de Alva (Eds.). De palabra y obra en el nuevo mundo, vol. 2 (pp. 349-378). México: Siglo XXI.

Pereira, M. (2013). La evangelización en la Ruta de La Plata, Arica y Parincota. Espacio Regional, 1(10), 31-44.

Platt, T. (1976). Espejos y maíz. Temas de estructura simbólica andinas. Cuadernos de investigación. La Paz: CIPLA.

Platt, T. (1980). Espejos y maíz. El concepto de yanantin entre los Macha de Bolivia. En Mayer, E. y Bolton, R. Parentesco y matrimonio en los Andes (pp. 139-182). Lima: Pontificia Universidad Católica del Perú, Fondo Editorial.

Platt, T. (2002). El feto agresivo. Parto, formación de la persona y mito-historia en los Andes. Estudios Atacameños, 22, $127-155$.

Poma de Ayala, G. (2008 [1615]). Nueva corónica y buen gobierno. Tomo II. Lima: Fondo de Cultura Económica.
Ponce, F. (1978). Población y familia en una zona rural de Arequipa pre-republicana. En Miró, F., Pease, F. y Sobrevilla, D. Historia, problema y promesa (pp. 473-489). Lima: Pontificia Universidad Católica del Perú.

Rabell, C. (1992). Matrimonio y raza en una parroquia rural: San Luis de la Paz, Guanajuato, 1715-1810. Historia Mexicana, XLII(1), 3-44.

Ramos, G. (2015). Sacred boundaries: parishes and the making of space in the colonial Andes. En Kominko, M. (Ed.). From Dust to Digital. Ten Years of the Endangered Archives Programme (pp. 225-258). Cambridge: Open Book Publishers. Recuperado de http://dx.doi. org/10.11647/OBP.0052O.

Ríos, W. (1988). Percepción de los Ritos de Transición en los Andes: continuidad y permanencia en Arica y Valle de Azapa. Tesis para optar al grado de Magíster en Historia, mención Etnohistoria, Universidad de Chile, Santiago.

Robichaux, D. (2001). Uso del método de la reconstitución de familias en las poblaciones indígenas. Papeles de población, 28, 99-129.

Robinson, D. (2003). Collaguas II: Lari Collaguas: economía, sociedad y población, 1604-1605. Lima-Nueva York: Pontificia Universidad Católica del Perú - Universidad de Siracusa.

Rodríguez, P. (2006). Iluminando sombras: ilegitimidad, abandono infantil y adopción en la historia colombiana. En O’Phelan, S. y Zegarra, M. (Eds.). Mujeres, familia y sociedad en la historia de América Latina, siglos XVIII-XIX (pp. 57-76). Lima: Pontificia Universidad Católica del Perú - Instituto Francés de Estudios Andinos - CENDOC-Mujer.

Salomon, F., Feltham, J. y Grosboll, S. (2009). La revisita de Sisicaya, 1588. Huarochirí veinte años antes de Dioses y Hombres. Lima: Pontificia Universidad Católica del Perú, Fondo Editorial.

Spedding, A. (1998). Contra-afinidad: algunos comentarios sobre el compadrazgo andino. En Arnold, D. (Comp.). Gente de Carne y Hueso. Las tramas del parentesco en los Andes (pp. 113-137). La Paz: CIASE - ILCA. 
Tandeter, E. (2000). Parentesco y estrategias matrimoniales. En Boleda, M. y Mercado, M. C. (Comps.). SEPOSAL. Seminario sobre Población y Sociedad en América Latina (pp. 253-266). Salta: Gredes - Universidad Nacional de Salta.

Tandeter, E. y Acosta, L. (2002). La transmisión de los apellidos entre los indígenas andinos, siglos XVII-XIX. Anuario del Archivo y Biblioteca Nacionales de Bolivia, 8, 355-369.

Taylor, G. (1987). Ritos y tradiciones de Huarochiri del siglo XVI. Lima: Instituto de Estudios Peruanos.

Van Kessel, J. (1989). La Iglesia Católica entre los aymaras. Santiago: Rehue.
Van Kessel, J. (1996). "Los aymaras contemporáneos de Chile". En Hidalgo, J. (Ed.). Etnografia: Sociedades indígenas contemporáneas y su ideología, vol. 2 (pp. 47-67). Santiago: Andrés Bello.

Vargas Ugarte, R. (1951-1952). Concilios Limenses (15511772). Tomos I y II. Lima.

Zonabend, F. (1981). ¿Por qué nominar? Los nombres de las personas en un pueblo francés: Minot-En-Châtillonnais. En Levi-Strauss, C. (Ed.). La identidad. Seminario interdisciplinario (pp. 289-321). Barcelona: Ediciones Petrel. 